\title{
A INCLUSÃO NO MERCADO DE TRABALHO DA PESSOA TRANSGENERO E A "DOLOROSA" ARTE DE SER NORMAL
}

\author{
Anna Priscylla Lima Prado ${ }^{1}$ \\ Isabele Bandeira De Moraes Dangelo ${ }^{2}$
}

\section{RESUMO}

Aborda a inclusão das pessoas trans no mercado de trabalho e as dificuldades ainda hoje existentes face ao preconceito e à ausência de políticas públicas eficazes. Propõe análise a partir de uma pauta Hermenêutica à luz dos Princípios específicos do Direito do Trabalho e de Princípios Constitucionais Fundamentais, para que sejam criadas normas específicas para a eliminar o preconceito e garantir presença e respeito à dignidade dos transgêneros no meio laboral. As linhas metodológicas adotadas conduziram ao estudo comparado de legislações e políticas públicas utilizadas nos Estados Unidos e em países da UE, para reafirmar a necessidade de esforços legislativos.

Palavras-chave: Transgênero, inclusão, Políticas públicas, Mercado de trabalho

\section{INCLUSION IN THE LABOR MARKET OF THE TRANSGENDERS PERSON AND THE "PAINFUL" ART OF BEING NORMAL}

\begin{abstract}
:
Addresses the inclusion of trans people in the labor market and the difficulties that still exist today in face of prejudice and the absence of effective public policies. It proposes analysis based on a Hermeneutical agenda in the light of the specific Principles of Labor Law and Fundamental Constitutional Principles, in order to create specific norms to eliminate prejudice and guarantee presence and respect for the dignity of transgender workers. The methodological guidelines adopted have led to a comparative study of legislation and public policies used in the United States and in EU countries to reaffirm need for legislative efforts.
\end{abstract}

Keywords: Transgenders, Inclusion, Public policy, Job market

\section{INTRODUÇÃO}

O presente estudo tem como objetivo geral a discussão sobre a inclusão no mercado de trabalho da pessoa transgenero e a "dolorosa" arte de ser normal. Para tanto, parte da premissa de que a identidade de gênero é um direito fundamental que deve ser

\footnotetext{
${ }^{1}$ Doutoranda em Direito pelo PPGD UFPE. Pesquisadora do Grupo de Pesquisa Direito do Trabalho e os Dilemas da Sociedade Contemporânea. Professora da UNINASSAU.

${ }^{2}$ Doutora em Direito. Membro da JUTRA. Líder do Grupo de Pesquisa Direito do Trabalho e os Dilemas da Sociedade Contemporânea. Professora da UPE, UFPE e UNINASSAU.
} 
respeitado no constitucionalismo de 1988 , como forma de efetivação do princípio da igualdade.

No Estado Democrático de Direito a pluralidade das diversidades, dentre elas, a de gênero deve ser abordada no seio da sociedade como forma de concretização de um dos objetivos da República Federativa Brasileira, ou seja, promoção do bem de todos sem qualquer forma de preconceito.

Entretanto, vivemos em uma sociedade com valores morais desusados e contraditórios, por vezes impregnado por preceitos religiosos que se sobrepõem à laicidade do Estado, especificamente, com a presença das bancadas religiosas nas diversas esferas do Poder Legislativo, que na maioria das vezes estigmatizam as pessoas transexuais e impedem a concretização dos seus direitos constitucionalmente tutelados, dentre estes, a sua inserção no mercado de trabalho.

Assim, a transsexualidade é uma típica questão enigmática que voeja pela sociedade. Ser transgenero em muitas sociedades preconceituosas tal qual a brasileira é ser tratado como caso patológico, é ter o que a ciência médica determina como Transtorno de Identidade de Gênero (CID $10 \mathrm{~F} 64^{3}$ ), nascer com um determinado sexo biológico, mas não se identificar com tal.

Desta forma, o objetivo específico é abordar a principiologia da igualdade no contexto da inserção no mercado de trabalho das pessoas transgenero, discorrendo sobre o conceito de transsexualidade, a história dos excluídos, os direitos trabalhistas e a sua tendência à padronização como forma de otimizar os lucros e o a "dolorosa" arte de ser normal das pessoas trans representado no esforço que fazem para se encaixarem nas molduras preestabelecidas pela sociedade e assim conseguir ter acesso aos postos de trabalho. O artigo analisa a partir de estudo comparativo com a legislação estrangeira, a necessidade elaboração de normas específicas de proteção para esse grupo de cidadãos.

$\mathrm{O}$ estudo adota como metodologia a descritiva analítica com fundamento em autores que abordam o tema, diante de uma realidade tão complexa na qual a identidade de gênero dos trans causa tamanha estigma em uma sociedade ainda baseada em valores patriarcais, presa aos costumes tradicionais frutos do Helenismo e da cultura judaico cristã.

${ }^{3}$ Classificação Internacional de Doenças e Problemas Relacionados à Saúde. CID 10 fornece códigos relativos à classificação de doenças e de uma grande variedade de sinais, sintomas, aspectos anormais, queixas, circunstâncias sociais e causas externas para ferimentos ou doenças. 
Não é de se negar que no decorrer dos 30 anos desde a aprovação da Constituição Federal houve ao menos o mínimo de evolução na efetivação dos direitos fundamentais, mas a realidade nos mostra que há um longo percurso ainda a ser traçado para que sejam assegurados os direitos mínimos vitais para existência e sobrevivência humana, dentre estes, a inserção e a proteção no mercado de trabalho para os transgeneros.

\section{A CONSTITUIÇÃO FEDERAL DE 1988 E O PRINCÍPIO DA IGUALDADE}

O novo constitucionalismo latino-americano tem como traço característico, o processo de formação histórica, econômica e cultural dos diversos povos que integram a América Latina.

Neste sentido, destacam-se as lições de Rolla (2012, p.333) sobre o constitucionalismo latino-americano:

Los rasgos esenciales de este cambio se pueden observar, principalmente, a través de tres elementos: a la naturaliza del processo constituyente, la aparición de uma idea diversa de Constitución, y el perfeccionamiento de las técnicas de garantia de los derechos fundamentales.

Assim este processo de constituinte, da passagem de regimes autoritários para democracias, possibilitou o surgimento de textos constitucionais analíticos, nos quais os cidadãos não exercem apenas seus direitos e cumprem os deveres, mas também devem participar ativamente das ações dos poderes públicos, uma vez que esta legitimidade advém da titularidade do próprio poder.

$\mathrm{O}$ século $\mathrm{XX}^{4}$ é o início do fortalecimento do constitucionalismo latinoamericano e das constituições de seus países, inaugurando uma nova forma de instituições representativas e construindo sistemas democráticos mais amplos, como forma de limitar os poderes das elites locais. (CAMPINHO, 2010).

Já o século XXI na América Latina é marcado por um desenvolvimento acerca dos estudos dos processos e jurisdição constitucional, uma vez que nos textos constitucionais vigentes foram incluídos direitos prestacionais, os quais o Estado tem o

${ }^{4}$ É a consagração do Estado Social de Direito com o texto Mexicano de 1917 (La primera constitución político-social del mundo no dizer de Trueba Urbina, embora pouco referida). (In DANTAS, 2013. p. 242). 
dever de efetivá-los, como explanado por Dantas, Castro e Barros:

O desenvolvimento em nossa região, dos estudos de Direito Processual Constitucional e Jurisdição Constitucional na América Latina, a ponto de já se ter afirmado que a ciência do DCP tem um desenvolvimento especialmente latino-americano. Neste quadro cabe, então, uma indagação inicial: a que se deve a eclosão destes estudos?

Antes de enfrentarmos esta questão (que em última análise é uma questão política com reflexos constitucionais) entendemos que dois fatores são decisivos à compreensão deste fenômeno:

(1) o desenvolvimento de um sentimento constitucional que, mesmo incipiente, já começa a ser sentido no cenário da maioria dos Estados Latino americanos e (2) a amplitude da matéria constitucional, com a inclusão nos textos matérias que vão além do conteúdo apenas político como defendido nos tempos do Liberalismo. (negrito no original).

No Brasil, a Constituição de 1988 tem o Ser Humano como centro das relações jurídicas e sociais assegurando o princípio da igualdade material e assim retratando no seu texto o homem de carne e osso, que tem os seus anseios, direitos, deveres, liberdades e por isso clama por dignidade, conforme retratava Ulysses Guimarães ${ }^{5}$ :

A Constituição Coragem - O homem é o problema da sociedade brasileira: sem salário, analfabeto, sem saúde, sem casa, portanto sem cidadania. A Constituição luta contra os bolsões de miséria que envergonham o País. Diferentemente das sete constituições anteriores, começa com o homem, que o homem é seu fim e sua primazia do homem, que foi escrita para o homem, que o homem é o seu fim e sua esperança. É a Constituição Cidadã. Cidadão é o que ganha, come, sabe, mora, pode se curar. A Constituição nasce do parto de profunda crise que abala as instituições e convulsiona a sociedade. Por isso mobiliza, entre outras, novas forças para o exercício do Governo e a Administração dos Impasses. O governo será praticado pelo Executivo o Legislativo. Eis a inovação da Constituição de 1988: dividir competências para vencer dificuldades. Contra a ingovernabilidade concentrada em um, possibilita a governabilidade de muitos. É a Constituição Coragem. Andou, imaginou, inovou, ousou, ouviu, viu, destroçou tabus. Tomou partido dos que só se salvam pela lei. A Constituição durará com a democracia e só com a democracia sobrevivem para o povo a Dignidade, a Liberdade e a Justiça. Brasília, 05 de outubro de 1988. (negritos nossos).

\footnotetext{
${ }^{5}$ Prefácio do Texto Constitucional de 1988 que foi retirado, após o seu lançamento pela edição do Centro Gráfico do Senado Federal já que só poderia haver um Preâmbulo.
} 
Assim no cenário nacional, segundo Edilson Nobre (2009, p. 214-215), a Constituição de 1988 representou um golpe no positivismo legalista, instalando um novo padrão de legalidade, orientado pela ideia de justiça, com a incorporação de valores e opções políticas em seu texto, sobretudo no que diz respeito à dignidade da pessoa humana e dos direitos fundamentais, retratados em suas normas e seus princípios.

Nesta "Constituição Cidadã", que prima pelo constitucionalismo social e pela efetivação dos direitos e garantias fundamentais, o princípio da igualdade passa a desempenhar um papel balizador para a fixação da interpretação constitucional e assim assegurar direitos as pessoas humanas independentemente da pluralidade das diversidades.

Sendo o princípio da igualdade tão importante na Constituição, torna-se, nas palavras de Bobbio (2004, p.62):

Critério supremo que permite estabelecer se uma norma pertence ao ordenamento; em outras palavras, é o fundamento de validade de todas as normas do sistema.

Quando se pensa em igualdade sob a ótica Aristotélica, automaticamente nos enveredamos pela máxima: “..tratar igualmente os iguais e desigualmente os desiguais..”, muito embora a sua concepção ser mais além do que a célebre passagem, já que a conceituação da igualdade para Aristóteles está relacionada ao conceito de justiça:

Desse modo, como o homem sem lei é injusto e o cumpridor da lei é justo, evidentemente todos os atos conforme a lei são justos em certo sentido, pois os atos prescritos pela arte do legislador são conforme a Lei, e dizemos que cada um deles é justo. Nas disposições sobre todos os assuntos as leis visam à vantagem comum, seja a de todos, seja a dos melhores ou daqueles que detêm o poder ou algo semelhante, de tal modo que, em certo sentido, chamamos justos os atos que tendem a produzir e a preservar a felicidade e os elementos que compõem para a sociedade política. (ARISTÓTELES, 2004, p. 15).

Logo no Estado Constitucional atual, a concepção de igualdade vai além da sua conceituação meramente formal de que todos são iguais perante a lei, já que deve ser reconhecido a ideia de igualdade nas diferenças. Porém "não se aspira uma igualdade que frustre e desabe as desigualdades que semeiam a riqueza humana da sociedade plural, nem se deseja uma desigualdade tão grande e injusta que impeça o homem de ser digno em sua existência e feliz em seu destino (ROCHA, 1991, p.118). 
Esta igualdade material submete todo o ordenamento a um tratamento justo, igualitário, para todo ser humano. Ressalta-se ainda a garantia da possibilidade de se favorecer a todos a oportunidade social, econômica, e cultural de afirmar esta igualdade perante toda a sociedade; a garantia de dar voz aqueles que querem ser reconhecidos como igualmente importantes na construção daquilo que chamam de civilização; a garantia que de forma programática toda desigualdade será posta em descrença, e posteriormente superada.

Constrange, assim, o legislador a não criar texto que venha confrontar as garantias daquele princípio; se, do contrário, não respeita, estará agindo inconstitucionalmente, bem como o aplicador do texto que deverá interpretar a norma mantendo os parâmetros de igualdade.

Pois o legislador, aplicador e particular deverão ficar longe da rotularização das pessoas em face das suas diversidades, compreendendo assim que a Constituição Federal de 1988, como garantidora de direitos, sem preferência de sexo, cor, gênero e orientação religiosa, ratificou que "toda pessoa humana tem o direito de ser identificada e igualada pela sua humanidade e diferenciada, no que constitui a sua individualidade". (ROCHA,2008.p 26).

A perspectiva da igualdade é, principalmente na constituição vigente, a de proteger o direito daqueles que ainda estão à margem na nossa sociedade. Como diz Leandro Franklin Gorsdorf (2014, p. 674) "processa-se então a verificação dos avanços pelo Estado quanto à ampliação da ideia de sujeito constitucional". Acrescentando esse autor que:

[...] desde 1988, não há a condenação de práticas sexuais, porém formalmente não houve um avanço a nenhuma normativa que instituísse direitos aos sujeitos LGBT. A ausência de leis garantidoras de direitos a estes grupos identitários se constitui espaço a ser preenchido, principalmente quanto a dizer sobre a ampliação do espectro da identidade deste sujeito constitucional. Notam-se avanços no Poder Executivo, no Poder Judiciário, mas uma estagnação, um bloqueio no processo legislativo, o que ocorre não é por falta de propostas de lei a serem discutidas. (2014, p. 682).

Dessa forma, no contexto do novo constitucionalismo visualizamos a aplicação da teoria queer, que propaga a ideia de superação do binarismo (masculino/feminino), a fim de desconstruir o paradigma entranhado em nossa sociedade, do reconhecimento do sujeito ou individuo por seu gênero ou pelo seu sexo. 
Afinal, porque levar em consideração o gênero ou a orientação sexual, para fins de se reconhecer ou não direitos? Ser transgênero é uma "dolorosa" arte de ser normal? E ser gente, não é tudo igual?

Neste sentido, não se pode conceber a adoção de leis ou posturas preconceituosas que impeçam a concretização de direitos vitais para as pessoas transgênero, como o direito a sua inserção no mercado de trabalho, uma vez que ser transgênero é ser gente, e como define Cármen Lúcia Antunes (2008, p 19):

Gente é igual. Tudo igual. Mesmo tendo cada um a sua diferença. Gente não muda. Muda o invólucro. O miolo, igual. Gente que ser feliz, tem medos, esperanças e esperas. Que cada qual vive a seu modo. Lida com as agonias e alegrias de um jeito único, só seu. Mas o sofrimento é sofrido igual. A alegria, sente-se igual.

Resguardar a dignidade e a igualdade da pessoa humana passa a ser um desafio diário, em uma sociedade impregnada por um conservadorismo exacerbado. Este é o desafio do constitucionalismo de 1988 que tem como premissa concretizar direitos a todos, uma vez que "não há distinção humanamente possível entre os homens" (ROCHA, 2008. p.26).

\section{DIREITO FUNDAMENTAL A IDENTIDADE DE GÊNERO DO TRANSEXUAL}

A identidade de gênero, contemporaneamente, vai além de uma concepção meramente binária entre homem e mulher, pois gênero é visto com um indivíduo se identifica com o outro e como este mesmo indivíduo pode se reconhecer em uma determinada sociedade, ou seja, uma análise muito mais ampla do que apenas uma perspectiva biológica/genital.

Neste sentido, é a lição de Ana Paula Ariston Barion Peres (2001, p.102), sobre a conceituação de identidade de gênero:

A identidade de gênero está relacionada com uma questão sentimental, como o indivíduo se sente com relação a sua identidade sexual, o papel de gênero diz respeito à colocação em prática da aprendizagem recebida e tem por objetivo não apenas encenar o papel sócio-sexual como também exteriorizar e retratar a identidade sexual do indivíduo. 
Assim, a identidade de gênero é conceituada como o sentimento de pertencer a um gênero e a sua capacidade de relacionamento de forma pacífica com esta identidade na realidade social. A identificação enquanto indivíduo é algo inato, irracional, pessoal, que está atrelada ao rol dos direitos de personalidade consagrados no art. $5^{\circ}$ da Constituição Federal de 1988.

A identidade de gênero segundo Judith Butler, reflete uma discussão que sai da conjuntura dos modelos tradicionais, para uma concepção construída à luz de uma perspectiva social:

[..] Essa formulação tira a concepção do gênero do solo de um modelo substancial da identidade, deslocando-a para um outro que requer concebê-lo como uma temporalidade social constituída. Significativamente, se o gênero é instituído mediante atos internamente descontínuos, então a aparência de substância é precisamente isso, uma identidade construída, uma realização performativa em que a platéia social mundana, incluindo os próprios atores, passa a acreditar, exercendo-a sob a forma de uma crença. (BUTLER, 2003, p.201)

Assim, a transsexualidade é entendida como uma incompatibilidade entre sexo biológico e o psicológico, "alguns transexuais se sentem incomodados (as) e até mesmo enojados (as) com os seus órgãos genitais. Eles não aceitam o seu sexo do nascimento" (MOREIRA, 2015.p. 31).

Desta forma, a afirmação de um sujeito enquanto transexual e o seu exercício na sociedade é um direito consagrado constitucionalmente atrelado ao princípio da igualdade, ou seja, a simples "arte" de ser gente.

A pessoa trans tem o direito a ser respeitada por sua identidade de gênero e deve ter acesso igualitário a sua inserção no mercado de trabalho, já que grande parte dos transexuais exercem empregos informais ou vão para a prostituição devido o preconceito social em relação a sua identidade de gênero. 
4. OS EXCLUÍDOS DA HISTÓRIA E DO DIREITO: uma trajetória de lutas e conquistas

Ao longo da evolução social os relatos históricos negaram de forma contínua o protagonismo a alguns sujeitos da sociedade. Figuras como a mulher, os próprios trabalhadores e os apenados tiveram sua voz silenciada e viveram na clandestinidade do contexto histórico tradicional.

Tal silencio, na verdade, não era restrito à História mas fazia parte de todo um contexto social eis que o direito à atuação estava em muitos aspectos cerceado e condicionado quase que exclusivamente à figura masculina padrão.

O mundo de hoje é um reflexo da ideologia capitalista, deste modo, para compreendê-lo em suas chagas e mazelas sociais necessário se faz conhecer o capitalismo em suas origens, crises e contradições.

Neste aspecto $^{6}$, para Michelle Perrot (2006), há duas situações nas quais se podem encontrar as mulheres no século XIX: as situações criadas pelas entidades públicas e as oriundas das avaliações pessoais. No primeiro caso, as impressões são quase que completamente elaboradas pelos homens, e assim sendo reproduzem as representações de como eles viam as mulheres, ou queriam que elas fossem vistas, o que dificulta conhecer as verdadeiras expectativas, sentimentos e visões que as mulheres estabeleceram sobre elas mesmas. Nos arquivos públicos, geralmente as mulheres apareciam quando perturbavam a ordem, muitas vezes na tentativa de subverter os papeis, ou através de greves (nas quais elas participavam bem menos que os homens) e manifestações acarretadas pela alta nos preços dos alimentos. Desta forma, Perrot concluiu que a desigualdade sexual e a marginalização ou desvalorização das atividades femininas contaminam as fontes referidas acima. As obras de Simone Beauvoir (2009) deixam transparecer claramente que toda a história das mulheres foi contada pelos homens. "Condenada a desempenhar o papel do outro, a mulher estava também condenada a possuir apenas uma força precária: escrava ou ídolo, nunca é ela que escolhe seu destino". (BEAUVOIR, 2009, p. 115)

\footnotetext{
${ }^{6}$ A fim de atingir os objetivos do presente artigo foi feito um corte epistemológico para tratar das questões específicas de gênero, mais precisamente os direitos laborais das pessoas transgênero, embora as autoras entendam que os excluídos da História e do Direito constituam um tecido social muito mais abrangente.
} 
Um grande reflexo desta marginalização se dá no mundo jurídico. O Direito como ciência não deve ser pensado como um fenômeno natural, que se apresenta no mundo real e não necessita de interpretação. Ao contrário, ele se encontra no mundo da ficção. As normas comportam significados e precisam de interpretação (as quais devem ser incessantemente renovadas para acompanhar o desenvolver das mudanças sociais).

Ellen Hazan assevera que "o direito não existe no imaginário humano a partir do ato de ler a norma e, sim, do ato de pensar a norma". (HAZAN, 2017, p. 48) É neste ponto que o Direito surge como fator de dominação e exercício de poder de uma classe sobre outra. Conforme René David: "o direito surge na defesa de uma classe dominante que em razão de seus interesses específicos, dita a proposta normativa que sirva à realização destes”. (DAVID, 1978, p. 71)

No mundo onde a sociedade se divide em conceitos binários (ou se é ou não é) quando o assunto é gênero, o homem é entendido como ser humano, a mulher como fêmea e as pessoas LGBTI são tratadas como doentes.

No que diz respeito ao Direito do Trabalho, com relação ao gênero, tudo o que existe se encontra voltado diretamente à proteção ao mercado de trabalho da mulher, trabalho este que na prática não tem conseguido proteger.

A fim de controlar a classe trabalhadora para que ela esteja sempre ao seu serviço, os empregadores a partir das Teorias Organizacionais fundamentam seus argumentos em quatro postulados básicos: exigência de capacitação para o trabalho, com o desenvolvimento de competências multifuncionais, competitivas, eficientes, capazes de integrar plenamente à organização da empresa; motivação ao empreendedorismo, a fim de fazer com que os funcionários disponibilizem suas habilidades a serviço da empresa; busca pelo enxugamento da corporação, por meio do incentivo à terceirização, à contratação de cooperativas e autônomos, bem como a formas alternativas de realização das suas atividades que fujam ao padrão da relação de emprego; e desestímulo aos movimentos sociais, especialmente, ao sindical, estabelecendo ideias reformistas e reconfortantes sobre a posição social e econômica aos trabalhadores. ${ }^{7}$

${ }^{7} \mathrm{O}$ professor Dr. Everaldo Gaspar Andrade é referência nacional e internacional no Direito do Trabalho e mais ainda quando o assunto é a teoria crítica do Direito do Trabalho. Possui - entre muitos outros trabalhos - uma trilogia em obras de leitura 
Por ser assim, é fácil compreender que a sociedade capitalista não tolera as diferenças, pois as diferenças perturbam a padronização por ela desejada que promove agilidade na prestação dos serviços e o maior lucro.

Segundo a Procuradora do Trabalho Sofia Vilela em sua tese doutoral:

"A discriminação por identidade de gênero no mercado de trabalho também deve ser avaliada na perspectiva desse tipo de organização, na qual a gestão de recursos humanos é voltada única e exclusivamente ao lucro e produtividade, não sendo preparada para lidar com a diferença". (VILELA, 2015, p. 119)

E arremata:

Os métodos da Teoria Organizacional Conservadora instalam a competição, o individualismo, a perseguição, a deslealdade, a flexibilização, tomando proporções maiores, quando o sujeito trabalhador não se enquadra nos padrões binários $\mathrm{e}$ heteronormativos no meio ambiente do trabalho. (VILELA, 2015, p. 119)

Em assim sendo, quais as respostas que o Direito do trabalho oferece para quem não se enquadra na moldura estabelecida pelo modo de produção capitalista?

O que se observa é que estas pessoas estão sendo "guetizadas", transformadas em verdadeiros refugos humanos, o que lhes resta para sobreviver é a marginalização e as profissões invisíveis. E ainda assim, quando conseguem acesso ao mercado de trabalho, carecem de normas específicas que os projetam, ficando a mercê da sorte ou do preconceito.

5. DIREITOS LABORAIS PARA DAS PESSOAS TRANSGÊNERO: caminhada iniciada, capítulo inconcluso

Recentemente, o Tribunal Superior do Trabalho manteve a condenação em face de uma autarquia federal, no valor de $\mathrm{R} \$ 30.000,00$ de indenização para uma

obrigatória para que desejar ir além dos manuais de Direito do Trabalho. Sobre a nota de rodapé, conferir em: ANDRADE, Everaldo Gaspar Lopes de. 0 direito do trabalho na filosofia e na teoria social crítica: os sentidos do trabalho subordinado na cultura e no poder das organizações. São Paulo: LTR, 2014. 
trabalhadora trans que sofria assédio moral no seu ambiente de trabalho. Dentre muitas violações, restou comprovado que ela não era autorizada a usar seu nome social no local de trabalho tampouco o banheiro feminino. É importante referir aqui que consta do processo que a trabalhadora não suportou todos os constrangimentos e pediu demissão, somente após ingressou com reclamação a trabalhista. ${ }^{8}$

Decisões como esta começam a acontecer timidamente no Brasil e muito a reboque do que tem sido decidido e legislado em outros países. Importante mencionar que decisões como a acima referida não estão fundamentadas em normas específicas sobre o assunto, em sua maioria são fruto de processos de integração das lacunas do Direito e por isso os direitos no caso laborais das pessoas Trans ficam condicionados à interpretação, empatia e sensibilidade dos julgadores, o que gera um quadro de insegurança jurídica, disparidade de decisões e incertezas.

Na verdade, data máxima vênia a decisão do Tribunal Superior do Trabalho foi até bastante suave, quando se leva em consideração o que se entende no Direito do Trabalho como dano existencial.

Agir o empregador de modo a prejudicar as relações sociais do trabalhador e o seu projeto de vida configura dano existencial. No Direito do Trabalho, esse tipo de dano vem ganhando destaque na doutrina e na jurisprudência.

Uma das autoras do presente artigo em trabalhos anteriores já havia se manifestado acerca da omissão da legislação sobre o dano existencial no que se refere ao tratamento discriminatório e situações análogas no contexto do trabalho da pessoa trans:

O julgado envolve um tema palpitante que começa a tomar corpo na doutrina brasileira. Na opinião desta articulista o dano existencial - tal como o assédio moral - se constitui como espécie do gênero - dano moral. A título de narrativa extraprocessual, registra a negligência dessa mesma doutrina, quanto à tipificação do dano existencial, na hipótese de discriminação por gênero e nas circunstâncias que vão além da

\footnotetext{
${ }^{8}$ Para ter acesso ao extrato da decisão (o número do processo não foi divulgado para proteger as partes), consultar o link: http://www.tst.jus.br/noticia-destaque/lasset publisher/NGo1/content/id/24249429.
} 
alternativa binária homem/mulher e envolve a comunidade LGBT (...).(D'ANGELO, 2015, p. 31) ${ }^{9}$

O dano existencial causa no trabalhador a frustração de uma realização pessoal, quer nas suas relações pessoais, quer em suas metas de vida. Desta forma, além dos elementos clássicos de qualquer forma de dano, deve-se avaliar dois outros elementos: o projeto de vida e a vida de relações.

Retirar em virtude do labor esse sentido de vida do trabalhador gerará um dano extrapatrimonial objetivo associado à sua própria existência. Todavia qualquer decisão neste sentido só é possível a partir de construções teóricas, uma vez que não temos normas específicas sobre o assunto.

Ao lado do cenário brasileiro, no contexto internacional desenvolve-se teorias e normas que entendem as autoras do presente artigo são importantes parâmetros para a informação dos direitos fundamentais dos trabalhadores transgênero.

Nos Estados Unidos foi realizada uma pesquisa acerca do tema chamada "Transgender Inclusion In The Work Place - 2nd edition A Human Right CampaignFundacion Report". Tal pesquisa publicada em 2008, no formato de relatório conta, dentre outros das normas criadas e medidas adotadas em defesa dos Direitos Civis e Laborais das pessoas trans nos Estados Unidos e em Países da Europa e é extremamente rica em informações, traz inclusive relatos de pessoas discriminadas. Observe-se o que aponta o relatório com relação à postura que se exige dos Estados membros dos Estados Unidos:

De acordo com as leis e ordenanças não discriminatórias que incluem a identidade de gênero, os empregadores são impedidos de demitir, recusar-se a contratar, recusar-se a promover ou de outra forma prejudicar um candidato ou empregado que tenha transição de gênero ou que planeje passar por uma transição de gênero, ou àqueles cujo sexo não corresponda ao do nascimento. Algumas leis e portarias protegem explicitamente a identidade de gênero percebida e a expressão de gênero, enquanto algumas também fornecem acesso a banheiros em locais públicos e locais de emprego (veja -Facilities: Grant Restroom e Locker Room Access de acordo com a Apresentação de Gênero em Tempo

\footnotetext{
${ }^{9}$ Para maiores informações sobre o assunto consultar o texto "Dano existencial Sujeição do empregado à jornada de trabalho extenuante de 15 horas diárias alternadamente" em Revista de Direito do Trabalho - RDT, ano 41, maio-junho de 2015.
} 
Integral de um Funcionárioll) (TRANSGENDER, 2008, p. 33) (tradução livre)

Até abril de 2008, nenhuma lei federal estadunidense protegia consistentemente as pessoas transgêneros contra a discriminação no local de trabalho. Desta forma em alguns Estados, as leis federais que impedem a discriminação baseada no sexo e na deficiência estavam sendo argumentadas como formas de abordagem para a proteção de trabalhadores transgêneros. Os resultados destes esforços foram o Employment Non-Discrimination Act (Ato de Não Discriminação no Emprego), introduzido no $110^{\circ}$ Congresso como H.R. 2015, acrescentou identidade de gênero à lei de não-discriminação existente. Uma versão do projeto de lei com apenas orientação sexual, H.R. 3685, foi aprovada em novembro de 2007 pela Câmara dos Deputados dos Estados Unidos. A partir de abril de 2008, mais de 50 grandes empresas se juntaram à Coalizão Empresarial para a Justiça no Trabalho, que apoia legislação que acrescentaria orientação sexual e identidade de gênero a classes existentes protegidas pela lei federal de emprego.

A figura abaixo mostra o mapa dos Estados Unidos e indica quais dos seus Estados proíbem a discriminação de gênero tanto na seara pública, como na privada.

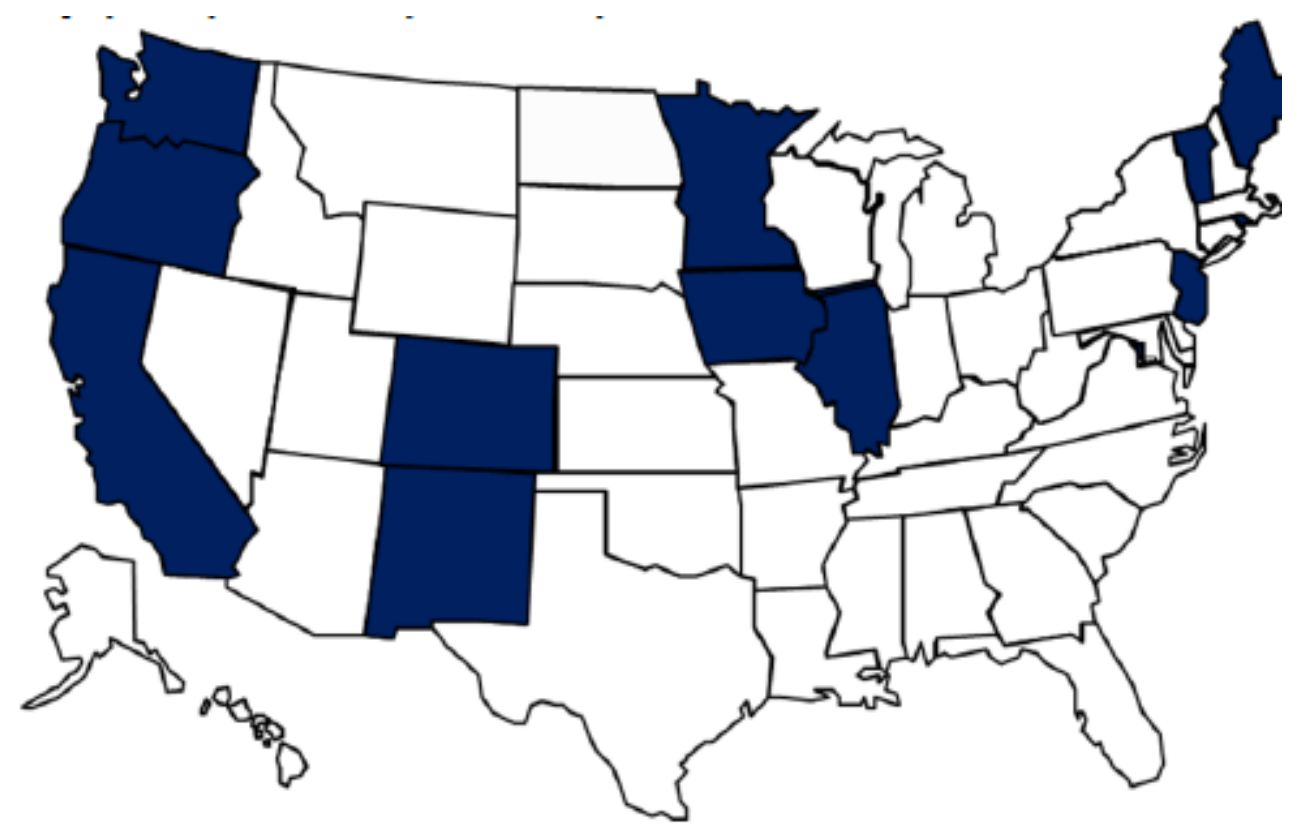

Califórnia (discriminação proibida baseada em identidade de gênero em 2003, orientação sexual 1992); Colorado (2007); Iowa (2007); Illinois (2005); Maine (2005); Minnesota (1993); New Jersey (identidade de gênero 2006, orientação sexual 1992); Novo México (2003); Oregon (2008); Rhode Island (identidade de gênero 2001, 
orientação sexual 1995); Vermont (identidade de gênero 2007, orientação sexual 1992); Washington (2006); E o Distrito de Columbia (identidade de gênero 2006, orientação sexual 1973). Nota: A partir de 2005, a lei do Havaí proíbe a discriminação baseada na identidade de gênero em habitações e acomodações públicas, porém não no emprego.

Figura 1. Estados que Proibem a Discriminação Baseada na Identidade de Gênero no Emprego Público e Privado (Ano Efetivo), a partir de $1^{\circ}$ de janeiro de 2008. (TRANSGENDER, 2008, p. 11) (tradução livre)

O relatório também traz dados sobre o assunto em países da União Européia. Com relação a eles as proteções de transgêneros são específicas nas leis de cada um dos país membros e informação sobre demandas judiciais é escassa. Enquanto alguns países fornecem proteções legais para pessoas trans, as empresas podem e devem estender as mesmas proteções para os funcionários transgêneros para suas operações globais. Assim como nos Estados Unidos, as questões internacionais transgênero estão evoluindo rapidamente.

Na União Européia, uma decisão do Tribunal de Justiça das Comunidades Européias de 1996 em PvS e no Conselho do Condado de Cornwall forneceu proteções contra a discriminação no emprego relacionada à "mudança de sexo". O Reino Unido formalizou esta decisão da UE quando da aprovação das Regulações de Discriminação Sexual (Reatribuição de gênero) de 1999. Esta lei prevê proteções para pessoas pretendentes a serem transexuais de sofrerem ou terem sidos submetidos à cirurgia de mudança de sexo, e se aplica a qualquer estágio de emprego.

O Tribunal Europeu dos Direitos do Homem continuou a defender e a exigir proteções para as pessoas transexuais, e tanto o Reino Unido quanto a Espanha também têm leis que permitem aos transgêneros mudarem o seu nome e gênero em documentos oficiais sem necessidade de serem submetidos a cirurgia.

Dois estudos realizados no Reino Unido - um realizado antes da decisão do TJCE e um depois da adopção da lei de 1999 relativa à não discriminação no Reino Unido - demonstram que, embora a discriminação dos trabalhadores transgéneros tenha diminuído, ela continua a ocorrer frequentemente. Antes da decisão do TJCE, 37 por cento das pessoas que haviam feito a transição e subseqüentemente mudaram de emprego alegaram que foram forçadas a sair. Após a promulgação da lei de não-discriminação de 1999., esta diminuiu para 16 por cento. No entanto, apenas metade das pessoas inquiridas foram autorizadas a utilizar o banheiro adequado durante a transição. 
Fora da Europa, a África do Sul e muitos estados e territórios da Austrália também proíbem a discriminação contra pessoas transgénero. As empresas que operam nesses países são proibidas e podem ser responsabilizadas por discriminação ou assédio de funcionários transgêneros. (TRANSGENDER, 2008, p. 13) (tradução livre)

Um grupo de renomados juristas em direito internacional desenvolveu os inovadores Princípios de Yogyakarta sobre orientação sexual e identidade de gênero em março de 2007, logo após a reunião de 2006 do Conselho de Direitos Humanos da ONU em que 54 países chamaram a atenção para violações de direitos humanos baseadas na orientação sexual, na identidade de gênero e na necessidade de tomar medidas para prevenir novos incidentes de abuso, repressão e discriminação. Tratam-se de 29 princípios que demandam ação das Nações Unidas, governos individuais entre outros para assegurar o alcance universal das proteções de direitos humanos para a comunidade LGBT. Além disso, apelam às empresas para que - reconheçam e ajam sobre o importante papel que tem em assegurar o respeito desses princípios em relação à sua própria força de trabalho e na promoção dos mesmos a nível nacional e internacional. ${ }^{10}$

6. A "DOLOROSA" ARTE DE SER NORMAL: a necessidade de normas específicas protetora das pessoas transgênero

A obra "A arte de ser normal", da autora Lisa Williamson ( conta a historia de David, um garoto adolescente que desde os oito anos de idade tem o desejo de ser uma menina e que está se preparando para contar aos pais que deseja fazer a cirurgia de mudança de sexo. A história se passa mesclando a vida escolar e familiar de David. O livro aborda também as ilusões de quem acredita que uma cirurgia bastará para resolver todos os seus problemas, como também trata da situação de quem já passou pelo procedimento e precisa enfrentar o preconceito das pessoas.

Mais informações sobre 0 assunto, consultar a página:
http://www.yogyakartaprinciples.org/


É muito doloroso se sentir diferente numa sociedade que nos impõe padronização e condutas preestabelecidas. Por isso as autoras do presente artigo entendem que é papel do Direito a fim de promover a paz e o bem social a criação de normas que tratem da questão das pessoas transgênero em todos os seus aspectos.

Em tal sentido, a esquerda pós-moderna faz uma crítica da modernidade, negando o conhecimento totalizante. Confrontam o movimento operário tradicional e o próprio marxismo, eis que entendem que os movimentos sociais não podem se reunir em torno de uma única bandeira de luta, uma vez que, no mundo contemporâneo, não há um interesse universal, mas sim particularidades étnicas, sexuais, de gênero, dentre tantas outras.

Nunca é demais recordar que todos os seres humanos nascem livres e iguais em dignidade e direitos e que todos sem exceção tem o direito de desfrutar da proteção aos Direitos Humanos sem distinção de cor, raça, religião, gênero, ou condição de nacional ou estrangeiro, posição econômica ou qualquer outra condição.

As articulistas entendem que identidade ou entendimento gênero significa uma experiência interna e individual do gênero como cada pessoa o sente em seu íntimo, o que pode ou não corresponder ao sexo atribuído à nascença, incluindo o senso pessoal do corpo - que pode envolver a modificação da aparência ou função corporal por meios médicos, cirúrgicos ou outros, desde que seja escolhido livremente e outras expressões do gênero.

Entendem ainda, que a aplicação dos direitos humanos deve levar em conta as situações específicas e experiências de pessoas de diversas orientações sexuais e identidades de gênero existentes. Desta forma, reafirma-se a fundamentalidade dos direitos das pessoas transgênero, seja na proteção dos direitos como à intimidade, à vida privada, ao direito ao nome, à afirmação de sua identidade de gênero, seja na esfera, direito à saúde, à educação e, especialmente, o direito ao trabalho.

\section{CONCLUSÕES}

O presente estudo propôs uma abordagem a inclusão da pessoa transgênero no mercado de trabalho a partir de uma visão que se fundamente em princípios 
Constitucionais Fundamentais, como o Princípio da Dignidade Humana e da Isonomia, assim como de princípios específicos do Direito do Trabalho, como o Princípio da Proteção.

Ao seguir o itinerário de estudo proposto, o artigo se deparou com o fato de que há muito ainda por se fazer no que diz respeito à concretização do exercício dos Direitos Fundamentais, ainda mais no que se refere aqueles que pertencem aos grupos de minorias do tecido social.

Foram apresentados e estudados conceitos basilares sobre identidade de gênero e transexualismo sob as perspectivas de autoras como Ana Paula Peres e Judith Butler e a sua contextualização nos direitos das "gentes".

Com o objetivo de deixar evidente o tratamento social destinado a determinados grupos de pessoas, foi inserido o título "os excluídos do Direito e da História", no qual se abordou a questão de gênero e as suas repercussões.

Em contexto, foi analisada recente decisão do Tribunal Superior do Trabalho, a partir da qual ficou claro para as autoras do presente artigo o vazio legislativo no que diz respeito a proteção ao mercado de trabalho para as pessoas trans, tanto com relação ao seu acesso, como na manutenção e na preservação da sua identidade e dignidade.

Buscou-se, a partir de estudos das realidades em países estrangeiros - nos quais já existe avanço no sentido de eliminar o preconceito à comunidade LGBT no mercado de trabalho, trazer propostas de situações de trabalho que já são vivenciadas em países como os Estados Unidos, e países membro da União Européia, para a concretização de seus Direitos Fundamentais no Brasil.

Por fim, fez-se uma análise, a partir da obra "A Arte de Ser Igual" o eterno sofrimento que é para estes seres humanos tentar todos os dias seguir os padrões sociais preestabelecidos, para só assim - se negando o direito de ser quem é - conseguir uma colocação profissional o que muitas vezes se dará nos trabalhos invisíveis. Diante de todos os argumentos desenvolvidos conclui-se pela necessidade da elaboração de normas específicas para a proteção do mercado de trabalho das pessoas trans, assim como de políticas públicas específicas que tenham o propósito de promover a efetivação de seus Direitos Fundamentais, como convém ao Estado Democrático de Direito. 


\section{REFERENCIAS}

ANDRADE, Everaldo Gaspar Lopes de. O direito do trabalho na filosofia e na teoria social crítica: os sentidos do trabalho subordinado na cultura e no poder das organizações. São Paulo: LTR, 2014.

ARISTÓTELES. Ética a Nicômano. Tradução de Pietro Nasseti. São Paulo: Martin Claret, 2004.

BARROSO. Luís Roberto. Judicialização, Ativismo Judicial e Legitimidade Democrática. Anuário Iberoamericano de Justiça Constitucional. número 13. Madrid, 2009.

BEAUVOIR, Simone de. O segundo sexo. Rio de Janeiro: Nova Fronteira, 2009.

BOBBIO, Norberto. A Era dos Direitos. São Paulo: CAMPUS, 2004.

BUTLER, J. (1990). Problemas de gênero - Feminismo e subversão de identidade. Rio de Janeiro: Civilização Brasileira, 2003.

CAMPINHO. Bernardo Brasil. A jurisdição constitucional e o processo democrático na experiência latino-americana contemporânea. In Anais do XIX Encontro Nacional do CONPEDI. Realizado em Fortaleza-CE nos dias 09, 10, 11 e 12 de junho de 2010.

DANTAS, Ivo; CASTRO. Gina Gouveia Pires de; BARROS. Lívia Dias. O novo Constitucionalismo Latino-Americano e o Controle de Constitucionalidade. Texto fornecido pelos autores.

Ivo. Teoria do Estado Contemporâneo. $2^{\text {a }}$ Ed. Revista, Atualizada e Ampliada. São Paulo: Editora Revista dos Tribunais, 2013.

DANGELO, Isabele Bandeira de Moraes. INDENIZAÇÃO - Dano existencial sujeição do empregado à jornada de trabalho extenuante de 15 horas diárias alternadamente. In: Revista de Direito do Trabalho - RDT. São Paulo: RDT, ano 41, vol. 163, maio-junho, 2015. 
DAVID, René. Os grandes sistemas do direito contemporâneo: direito comparado. Lisboa: Meridiano, 1978.

GORSDORF, Leandro Franklin. Direitos "LGBT" e a identidade do sujeito constitucional: um caminho para além do arco-íris. In: Direito constitucional brasileiro: volume I: teoria da constituição e direitos fundamentais/ Clèmerson Merlin Clève, coordenador; coordenadora assistente Ana Lucia Pretto Pereira. São Paulo: Editora Revista dos Tribunais, 2014

HAZAN, Elen Mara Ferraz. Mulheres na efetivação dos direitos humanos e sociais. Belo Horizonte: RTM, 2017.

MOREIRA, Izabel Rosa. Diversidade sexual como direito fundamental: o reconhecimento jurídico da homoafetividade no Brasil. Curitiba: Juruá, 2015.

NOBRE JÚNIOR, Edilson Pereira. Administração pública, legalidade e póspositivismo. In: BRANDÃO, Cláudio; CAVALCANTI, Francisco de Queiroz Bezerra; ADEODATO, João Maurício (Coord.). Princípio da legalidade: da dogmática jurídica à teoria do direito. Rio de Janeiro: Forense, 2009.

PERROT, Michelle. Os excluídos da história. Operários, mulheres e prisioneiros. São Paulo: Paz e Terra, 2006.

PERES. Ana Paula Ariston Barion. Transsexualismo: o Direito a uma nova identidade sexual. Rio de Janeiro. Renovar, 2001.

ROCHA, Cármen Lúcia Antunes. O princípio constitucional da igualdade. Belo Horizonte: Lê, 1991.

, Cármen Lúcia Antunes. Direitos de para todos. $2^{\mathrm{a}}$ ed. Belo Horizonte: Fórum, 2008.

ROLLA, Giancarlo. La evolución del constitucionalismo em América Latina y la originalidade de las experiencias de justicia constitucional. Anuário Iberoamericano de Justiça Constitucional. número 16. Madrid, 2012.

SILVA, Sofia Vilela de Moraes e. Discriminação por identidade de gênero no direito do trabalho: a desconsideração do dispositivo binário centrado na polaridade 
homem/mulher, para ampliar os cânones da proteção. Recife: Tese de Doutorado.

Programa de Pós-Graduação em Direito da UFPE, texto avulso, 2015.

TST. Mantida indenização a trabalhadora que sofreu assédio moral por ser transexual. in http://www.tst.jus.br/noticia-destaque/-/asset_publisher/NGo1/content/id/24249429.

Consultado em 08/05/2017.

WILLIAMSON, Lisa. A arte de ser normal. Rio de Janeiro: Rocco, 2015.

YOGYAKARTA. http://www.yogyakartaprinciples.org/. Consultado em: 08/05/2017.

TRANSGENDER INCLUSION IN THE WORK PLACE - 2ND EDITION A HUMAN RIGHT CAMPAIGNFUNDACION REPORT . In:

http://www.hrc.org/issues/9603.htm. Consultado em: 05/05/2017. 